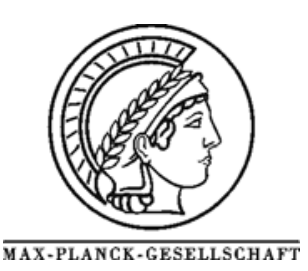

\title{
Combined in-situ XPS and PTRMS Study of Ethylene Epoxidation over Silver
}

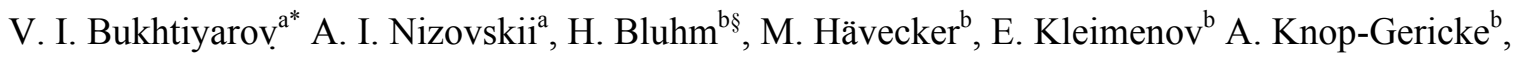 \\ R. Schlögl ${ }^{\mathrm{b}}$
}

\author{
${ }^{a}$ Boreskov Institute of Catalysis, Lavrentieva ave. 5, Novosibirsk, 630090, Russia \\ ${ }^{b}$ Department of Inorganic Chemistry, Fritz-Haber-Institute of the MPG, Faradayweg 4-6, 14195 Berlin, Germany \\ $\S$ present address: Lawrence Berkeley National Laboratory, Chemical Sciences Division, Berkeley, CA 94720 \\ *author to whom correspondence should be addressed
}

Received 31 March 2005; revised 5 November 2005; accepted 21 November 2005; available online 18 January 2006.

\begin{abstract}
Ethylene epoxidation over silver was investigated by combined in-situ X-ray photoelectron spectroscopy (XPS) and proton-transfer reaction mass-spectrometry (PTRMS) at temperatures from 300 to $520 \mathrm{~K}$ and in the pressure range from 0.07 to 1 mbar. Ethylene oxide was present among the reaction products at $\mathrm{T} \geq 420 \mathrm{~K}$ and $\mathrm{P} \geq 0.3$ mbar. The catalytically active surface contains two oxygen species - nucleophilic and electrophilic oxygen. The observed correlation between the abundance of electrophilic oxygen and the yield of ethylene oxide expressed as $\mathrm{C}_{2} \mathrm{H}_{4} \mathrm{O}$ partial pressure indicates that namely this oxygen species oxidizes ethylene to ethylene oxide. Opposite trend is observed for nucleophilic oxygen: the higher is the abundance of this species, the lower is the yield of ethylene oxide. This result is in line with the known fact that nucleophilic oxygen due to its oxidic nature is active in total oxidation of ethylene to $\mathrm{CO}_{2}$ and $\mathrm{H}_{2} \mathrm{O}$. The low activity of silver at $\mathrm{T}<420 \mathrm{~K}$ is caused by the presence of carbonates and carbonaceous residues at the silver surface that reduce the available silver surface area for the catalytic reaction. Reduction of the surface area available for the formation of active species due to accumulation of the embedded oxygen species explains also the decrease of the rate of ethylene oxide formation with time observed for $\mathrm{T} \geq 470 \mathrm{~K}$.
\end{abstract}

Keywords: Silver, Catalyst, Oxygen, Ethylene, Epoxidation, In situ XPS, PTMRS

\section{Introduction}

The relationship between the structure of a catalyst and its catalytic activity has motivated many investigations which have applied surface-sensitive methods to study heterogeneous catalytic systems. These experiments were focused on the chemical composition and morphology of catalyst surfaces, the nature of adsorbed species and reaction intermediates. Most of these studies were performed $e x$-situ, i.e. not in the presence of the reaction gas mixture, and a-priori transfer of the results of these studies to technical catalysis is difficult due to the pressure gap problem. The evacuation of the reaction gas mixtures, which is usual step in the post-reaction analysis, can lead to the destruction of the active centers on the catalyst surface due to the removal of, e.g., weakly bound species or a change of the chemical nature of the surface constituents. As a consequence, catalyst surfaces under operating catalytic conditions $(\mathrm{P}>1$ mbar) can be quite different from the same surfaces when investigated using physical methods under high vacuum conditions $\left(\mathrm{P}<10^{-6} \mathrm{mbar}\right)$.

Silver catalysts for ethylene epoxidation have in the past also mostly been studied under ex situ conditions with high-vacuum based surface science techniques [1-8]. Our own previous studies were also not free from this drawback $[9,10]$. Partly due to the absence of real in-situ investigations, the exact mechanism of this reaction is still under debate. Two aspects are mainly under discussion: on one hand the nature of the epoxidizing oxygen [1-4], and on the other hand the nature of the key intermediate that leads to the formation of ethylene oxide. Both oxametallacycle $[11,12]$ and $\pi$-bonded ethylene $[3,8,13]$ are discussed in the 
literature, but on the basis of the currently available data it is difficult to determine which species (or both) is indeed the intermediate in the epoxidation route. Recent microkinetic modeling investigations $[14,15]$ allowed the elucidation of some aspects of the reaction mechanism. However, experimental studies under in-situ conditions, which will provide a direct correlation between the catalytic activity and the surface composition, have not been performed so far.

In recent years a number of techniques have been adapted to operate under reaction conditions ( $>0.1 \mathrm{mbar}$ ), such as X-ray absorption spectroscopy (XAS) [16,17], sum frequency generation (SFG) [18,19], infrared absorption spectroscopy (IRAS) [20,21], and scanning tunneling microscopy (STM) [23,24]. However, in most cases their application to catalytic systems can not be considered as a real in-situ study, because catalytic performance could not be measured simultaneously with an analysis of the catalyst surface. This makes it difficult to correlate the nature of the species adsorbed on a catalyst surface with its catalytic activity and/or selectivity. As a consequence, the surface species observed even at elevated pressures can not be directly attributed to catalytically active species.

In this paper, we present the results of simultaneously performed in situ X-ray photoelectron spectroscopy (XPS) and proton-transfer reaction mass spectrometry (PTRMS) experiments of the ethylene epoxidation over silver. Due to its versatility and sensitivity to the chemical state of an element, XPS is one of the most powerful methods for studying the surface of heterogeneous catalysts. Insitu XPS has been used in the past to study catalysts under reaction conditions at pressures of up to 2 mbar [24-29]. We have measured the yield of ethylene oxide using PTRMS. A detailed description of PTRMS can be found in Ref. 30. In brief, the ionization of gas phase molecules for the subsequent mass spectrometric analysis proceeds via the transfer of protons from $\mathrm{H}_{3} \mathrm{O}^{+}$ions, which are generated in a special source, to the analyzed substance. As a consequence, the method deals with a molecular ion, which has a greater mass (plus one proton) than the ion in the routine mass-spectrometric analysis. Only those ions with a higher proton affinity than $\mathrm{H}_{2} \mathrm{O}$ will contribute to the PTRMS spectrum. This ionization method does less fragment the analyzed molecules, which simplifies the analysis of mass spectra. Another advantage of PTRMS is its high sensitivity to organic molecules, such as ethylene and ethylene oxide.

We have studied the ethylene epoxidation over silver in the temperature range from 300 to $520 \mathrm{~K}$ and under varying total pressures and ethylene-to-oxygen mixing ratios. Our combined PTRMS and in situ XPS experiments show that the composition of the oxygen overlayer on a silver surface correlates with the yield of ethylene oxide. Based on these data we discuss a reaction mechanism for the ethylene epoxidation over silver.

\section{Experimental}

The experiments were performed at beam line U49/2-PGM1 at BESSY in Berlin [31]. The prototype of the XPS instrument was described earlier [28-29]. The key feature of this apparatus is an electrostatic lens system that focuses the electrons that are emitted by the sample (which is in a pressure of up to several mbar) into the focal plane of a hemispherical analyzer, which is situated downstream, in the high-vacuum region. The overall spectral resolution in our measurements was better than $0.3 \mathrm{eV}$, calibrated by Ar2p gas phase spectra. All spectra were normalized to the incident photon flux, which was measured with a photodiode of known quantum efficiency. The binding energies were calibrated against the Fermi edge of the sample. The incident photon energies in the measurements were $850 \mathrm{eV}$ for $\mathrm{O} 1 \mathrm{~s}, 700 \mathrm{eV}$ for $\mathrm{Ag} 3 \mathrm{~d}$, and $610 \mathrm{eV}$ for $\mathrm{C} 1 \mathrm{~s}$, which results in similar electron kinetic energies of $\sim 225 \mathrm{eV}$ and therefore a similar probing depth in the $\mathrm{O} 1 \mathrm{~s}, \mathrm{Ag} 3 \mathrm{~d}$, and $\mathrm{C} 1 \mathrm{~s}$ measurements. These kinetic energies correspond to inelastic mean free path lengths of the photoelectrons in a solid of about $10 \AA$. Since the electrons were detected under an angle of $55 \mathrm{deg}$ to the surface normal, the effective probing depth in our experiments was even smaller.

The ethylene and oxygen flows into the experimental cell were regulated with calibrated mass flow controllers. The overall ethylene and oxygen pressure in the experimental cell was varied from 0.071 to 1.05 mbar, and the ratio of $\mathrm{C}_{2} \mathrm{H}_{4}: \mathrm{O}_{2}$ partial pressures from about 1:10 to $1: 1$. Mass spectra were measured using a PTRMS produced by Ionicon Analytik (Austria). The ethylene pressure was monitored at $\mathrm{m} / \mathrm{z}=29\left(\mathrm{C}_{2} \mathrm{H}_{4}\right.$ plus $\left.\mathrm{H}^{+}\right)$, while the ethylene oxide pressure was monitored at $\mathrm{m} / \mathrm{z}=45\left(\mathrm{C}_{2} \mathrm{H}_{4} \mathrm{O}\right.$ plus $\left.\mathrm{H}^{+}\right)$. Due to its low proton affinity, $\mathrm{CO}_{2}$ did not contribute to the PTRMS signal at $\mathrm{m} / \mathrm{z}=45$. This was confirmed by the absence of a PTRMS signal at $\mathrm{m} / \mathrm{z}=45$ in a blank experiment when 0.1 mbar $\mathrm{CO}_{2}$ was admitted to the gas cell. As a consequence, carbon dioxide was not measured in our experiments.

Since in our setup the PTRMS is connected to the reaction chamber via a capillary and a leak valve, which lead to an essential drop of the pressures between the reaction cell and mass-spectrometer, PTRMS signals measured experimentally reflect the concentrations of gas phase molecules inside the mass-spectrometer, but not in the reaction volume. Moreover, the gas flow to the PTRMS was regulated by the leak valve that was necessary to avoid the overloading of the PTRMS signal. Normal operation of the PTRMS is possible if the concentration of the analyzed gas does not exceed 70000-80000 ppb. Consequently, the absolute values of the PTRMS signals were determined both by the pressure in the gas cell and by the pressure drop from the reactor to the mass spectrometer, which can be different for different experiments. The value of the pressure drop (A) was determined by comparison of the PTRMS signal of ethylene $(\mathrm{C}(\mathrm{Et}))$ with its partial pressure $(\mathrm{P}(\mathrm{Et}))$ measured in reaction cell using Baratron vacuum gauge: 


$$
\mathrm{A}_{\mathrm{i}}(\mathrm{Et})=\mathrm{P}_{\mathrm{i}}(\mathrm{Et}) / \mathrm{C}_{\mathrm{i}}(\mathrm{Et}),
$$

where index i means the different experiments. The choice of ethylene as calibrating gas is explained by two reasons. First, PTRMS is sensitive to ethylene, i.e. its proton affinity is higher than that of $\mathrm{H}_{3} \mathrm{O}^{+}$, and second, PTRMS signal of ethylene was almost stable in one experiment due to low conversion of ethylene under the reaction conditions used (see below). The latter allowed us to check the calibration from time to time. The linearity of the dependence (1) was checked in blank experiment when ethylene partial pressure was varied from 0.02 to 0.1 mbar. The measured PTRMS signal was varied from 11000 to about $54000 \mathrm{ppb}$ that demonstrates the quantitative correspondence of the values of PTRMS signals and partial pressures in the reaction cell.

To recalibrate the PTRMS signals of ethylene oxide to the corresponding values of partial pressures the following equation was used:

$$
\mathrm{P}_{\mathrm{i}}(\mathrm{EtO})=\mathrm{C}_{\mathrm{i}}(\mathrm{EtO}) / \mathrm{C}_{\mathrm{i}}(\mathrm{Et}) \times \mathrm{P}_{\mathrm{i}}(\mathrm{Et})=\mathrm{C}_{\mathrm{i}}(\mathrm{EtO}) \times \mathrm{A}_{\mathrm{i}}(\mathrm{Et}) .
$$

This equation suggests that ethylene oxide exhibits the same (or similar) proton affinity as ethylene. In general case, the proton affinities of ethylene and ethylene oxide or their probabilities to react with $\mathrm{H}_{3} \mathrm{O}^{+}$could be quite different. This difference in proton affinities can be taken into account by simple introduction to the equation (2) of some coefficient which is equal to the ratio of proton affinities (PA) and normalizes the calculated partial pressure of ethylene oxide $\left(\mathrm{P}_{\text {calc }}\right)$ to the real one $\left(\mathrm{P}_{\text {real }}\right)$ :

$$
\begin{aligned}
& \mathrm{P}_{\text {real }, \mathrm{i}}(\mathrm{EtO})=\mathrm{P}_{\text {calc,i }}(\mathrm{EtO}) \times \mathrm{k}=\mathrm{P}_{\text {calc }, \mathrm{i}}(\mathrm{EtO}) \times \\
& \mathrm{PA}\left(\mathrm{C}_{2} \mathrm{H}_{4}\right) / \mathrm{PA}\left(\mathrm{C}_{2} \mathrm{H}_{4} \mathrm{O}\right) .
\end{aligned}
$$

However, this coefficient must be identical for different experiments. Then, the neglect by $\mathrm{k}$ will result in absolute, but not relative error. Consequently, this will not affect the comparison of the results of experiments performed under different conditions.

The sample was a polycrystalline $\mathrm{Ag}$ foil $(99.99 \%$ purity) mounted on a temperature-controlled heating stage. The sample was cleaned by the standard cleaning procedure: $\mathrm{Ar}^{+}$sputtering, annealing in $10 \mathrm{mbar}^{\circ} \mathrm{O}_{2}$ at $570 \mathrm{~K}$, and flashing up to $800 \mathrm{~K}$ in vacuum [1-7]. Due to the residual gas pressure of $10^{-8}$ mbar in our chamber, the sample at room temperature was always covered by some hydrocarbon contaminants. However, when the sample was heated to $>420 \mathrm{~K}$ in the reaction mixture (or in pure $\mathrm{O}_{2}$ ), this contamination vanished. Other impurities were not observed after the cleaning procedure within the XPS sensitivity limit. The sample temperature was measured with an alumel-chromel thermocouple attached directly to the backside of the sample.

\section{Results}

Fig. 1 shows the PTRMS signals of ethylene and ethylene oxide recalibrated to the pressure units (see Experimental) as a function of temperature and time Two sets of conditions were applied in these experiments: (a) $\mathrm{P}\left(\mathrm{C}_{2} \mathrm{H}_{4}\right)=0.1$ mbar, $\mathrm{P}\left(\mathrm{O}_{2}\right)=0.25$ mbar; and (b) $\mathrm{P}\left(\mathrm{C}_{2} \mathrm{H}_{4}\right)=$ 0.24 mbar, $\mathrm{P}\left(\mathrm{O}_{2}\right)=0.25$ mbar. The last parts of the curves were measured at $\mathrm{T}=470 \mathrm{~K}$ (a) and $520 \mathrm{~K}$ (b), respectively, after stopping the oxygen flow. While the ethylene signal does not vary for the duration of the experiment (i.e. for more than 5 hours), the PTRMS signal from ethylene oxide increases with temperature. After stopping the $\mathrm{O}_{2}$ flow the PTRMS signal of ethylene oxide decreases rapidly to the background level. These results indicate that in the millibar pressure range and at $\mathrm{T} \geq 420 \mathrm{~K}$ ethylene oxide is formed as a result of ethylene epoxidation over silver. This conclusion is also confirmed by data from a blank experiment, which shows that the temperature-controlled heating stage (heater and power wires) in the absence of the silver does not produce ethylene oxide in the temperature range that was investigated in our experiments $(300-600 \mathrm{~K})$. From Fig 1 it is obvious that with increasing catalyst temperature the catalytic activity of silver in the ethylene epoxidation is increased. This trend has been earlier reported by Campbell [1-2]. From the PTRMS data it also follows that the catalytic activity is constant at $420 \mathrm{~K}$, while it decreases with time at $470 \mathrm{~K}$ and at higher temperatures. This observation points to a deactivation of the catalyst at $\mathrm{T} \geq$ $470 \mathrm{~K}$.

The permanency of the PTRMS signal from ethylene is due to the low conversion of ethylene to ethylene oxide in our experiments. The PTRMS signals from $\mathrm{C}_{2} \mathrm{H}_{4}$ are higher than the signals from $\mathrm{C}_{2} \mathrm{H}_{4} \mathrm{O}$ by a factor of $25-50$,

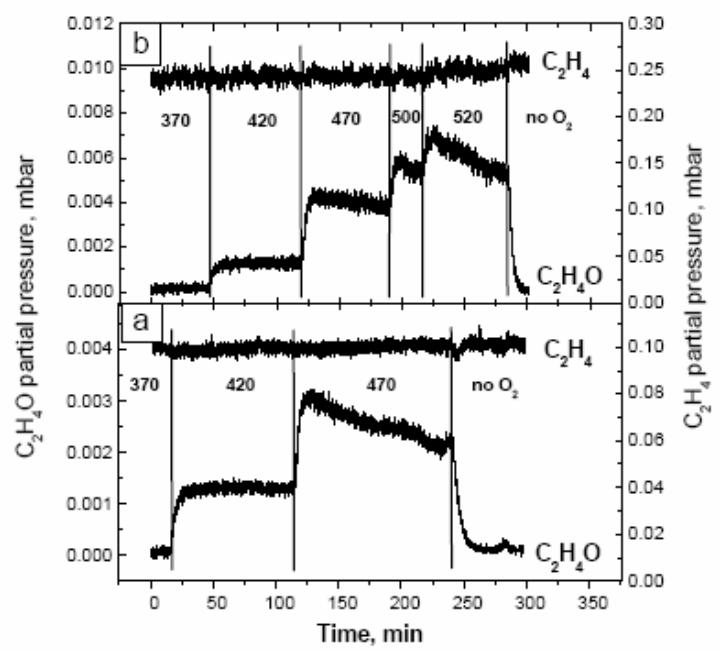

Figure 1: Variation of the PTRMS signals from ethylene and ethylene oxide with temperature, measured in reaction mixtures of (a) $\mathrm{P}\left(\mathrm{C}_{2} \mathrm{H}_{4}\right)=0.1$ mbar, $\mathrm{P}\left(\mathrm{O}_{2}\right)=0.25$ mbar; (b) $\mathrm{P}\left(\mathrm{C}_{2} \mathrm{H}_{4}\right)=0.24$ mbar, $\mathrm{P}\left(\mathrm{O}_{2}\right)=0.25$ mbar. The last parts of the curves were measured after stopping the oxygen flow. PTRMS signals were converted to the partial pressures in reaction cell (see Experimental). 

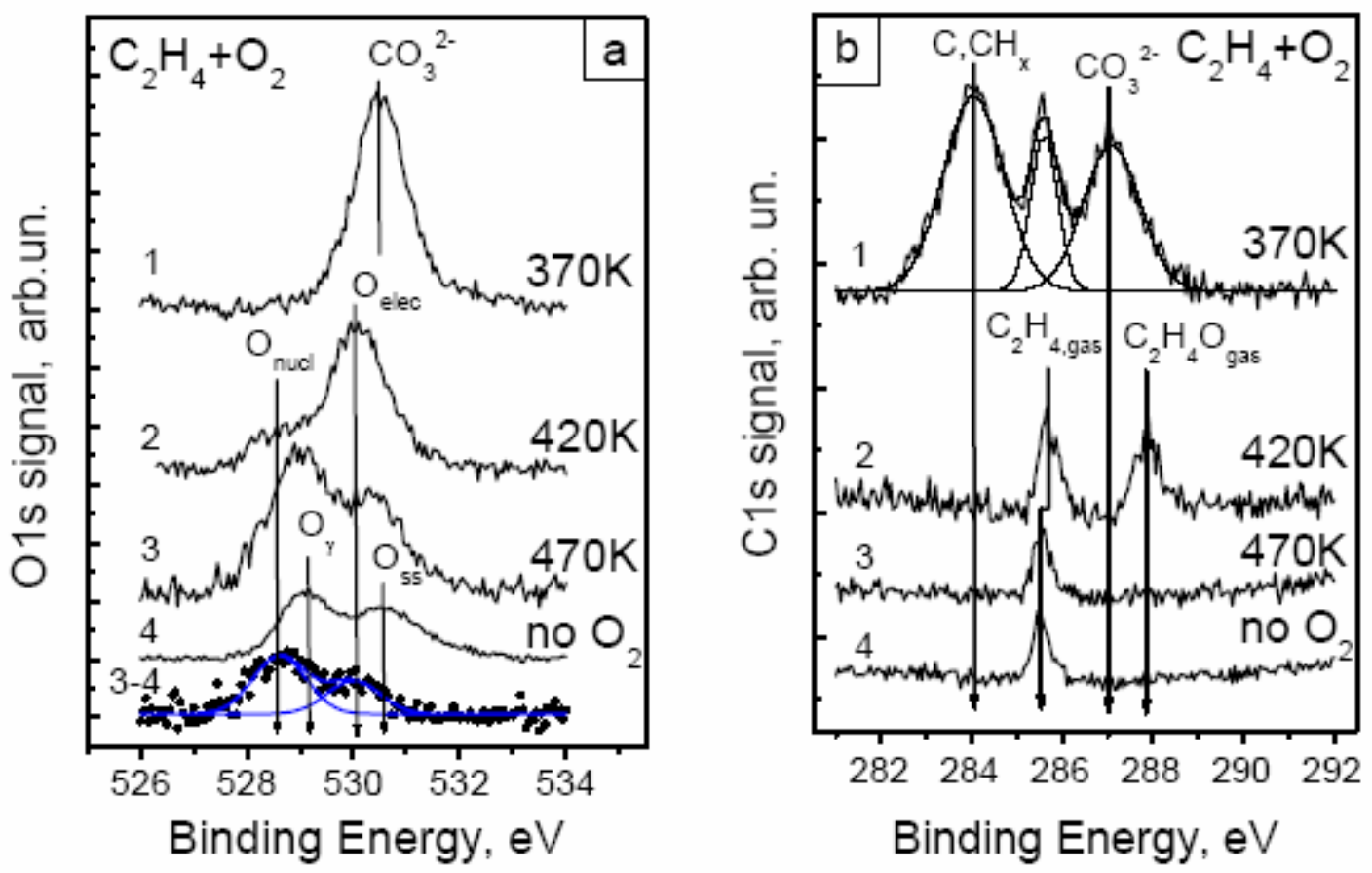

Figure 2: $\mathrm{O} 1 \mathrm{~s}$ (a) and $\mathrm{C} 1 \mathrm{~s}$ (b) spectra measured in-situ under the reaction mixture flow at $\mathrm{P}\left(\mathrm{C}_{2} \mathrm{H}_{4}\right)=0.1 \mathrm{mbar}, \mathrm{P}\left(\mathrm{O}_{2}\right)=0.25 \mathrm{mbar}$ and at various temperatures: $1-370 \mathrm{~K}, 2-420 \mathrm{~K}, 3-470 \mathrm{~K}$. Spectrum (4) was measured at $470 \mathrm{~K}$ after the oxygen flow was stopped. The difference spectrum between the measurements in the reaction mixture and in pure ethylene (3-4) shows peaks that exist on the surface only under reaction conditions.

and therefore the variations of the ethylene pressure due to its conversion to ethylene oxide are within the noise level of the $\mathrm{C}_{2} \mathrm{H}_{4}$ signal.

The $\mathrm{O} 1 \mathrm{~s}$ and $\mathrm{C} 1 \mathrm{~s}$ spectra measured in situ simultaneously with the PTRMS data in Fig. 1a $\left(\mathrm{P}\left(\mathrm{C}_{2} \mathrm{H}_{4}\right)=0.1 \mathrm{mbar}\right.$, $\mathrm{P}\left(\mathrm{O}_{2}\right)=0.25$ mbar) are shown in Fig. 2. All O1s spectra were normalized to the integrated intensity of the $\mathrm{Ag} 3 \mathrm{~d}_{5 / 2}$ peak. The spectra change strongly with temperature. At 370 $\mathrm{K}$, the silver surface was characterized by a single $\mathrm{O} 1 \mathrm{~s}$ peak at $530.5 \mathrm{eV}$ and three $\mathrm{C} 1 \mathrm{~s}$ peaks at 284.2, 285.8 and $287.3 \mathrm{eV}$ (Fig. 2, curves 1). Heating the sample to $420 \mathrm{~K}$ changes the spectra completely. At this temperature, the O1s spectrum exhibits a main peak at $530.0 \mathrm{eV}$ with a shoulder at about $528.5 \mathrm{eV}$, while the $\mathrm{C} 1 \mathrm{~s}$ spectrum exhibits two separate narrow peaks at 285.8 and $287.9 \mathrm{eV}$ (Fig. 2 , curves 2). Upon further increase of the temperature to $470 \mathrm{~K}$ the $\mathrm{C} 1 \mathrm{~s}$ peak at $287.9 \mathrm{eV}$ disappears (Fig. 2b, curve $3)$. The complex shape of the O1s spectrum measured at this temperature suggests that more than two peaks are present in this spectrum (Fig. 2a, curve 3). The O1s spectrum measured after stopping the $\mathrm{O}_{2}$ flow exhibits two peaks at 529.1 and $530.6 \mathrm{eV}$ (Fig. 2a, curve 4). The difference spectrum of the $\mathrm{O} 1 \mathrm{~s}$ spectra measured at $470 \mathrm{~K}$ in the reaction mixture and in pure ethylene (Fig. 2a, curve 3-4) shows two O1s peaks which are absent in the spectrum taken in pure ethylene. These peaks have the same binding energies of 528.5 and $530.0 \mathrm{eV}$ as the features observed in the spectrum at $420 \mathrm{~K}$.

In spite of the apparent complexity of this picture of the XPS spectra transformations, numerous literature data published earlier [1-12,32-36] allows us to attribute all XPS signals to surface and gas phase species. Although gas phase molecules do not contribute to XPS spectra under UHV conditions, at elevated pressure of in-situ experiments their concentration in the volume over the sample surface irradiated by the incident X-ray beam can become comparable with the concentration of surface species. And indeed, as shown by us earlier, measurable gas phase XPS signals appeared in similar experiments when pressure exceeds 0.05 mbar [6,27-28]. Gas phase molecules, however, exhibit generally narrower XPS lines than surface species. This suggests that $\mathrm{C} 1 \mathrm{~s}$ features at 285.8 and $287.9 \mathrm{eV}$ originates from gas phase species. Assignment of these $\mathrm{C} 1 \mathrm{~s}$ features to gas phase molecules can be made if one takes into account the composition of the gas phase in the studied system. The signal at $285.7 \mathrm{eV}$ is most likely due to gas phase ethylene. A permanency of its intensity after stopping of oxygen flow is additional argument in a favor of this assignment. From the BE of the other C1s peak (287.9 $\mathrm{eV}$ ) we can conclude that it is due to gas phase ethylene oxide which has a BE that is $2 \mathrm{eV}$ higher than that of gaseous ethylene [37]. This assignment requires additional discussion, since relatively high XPS intensity attributed to $\mathrm{C}_{2} \mathrm{H}_{4} \mathrm{O}$ is in apparent contradiction to the low intensity of its PTRMS signal (Fig .1). This contradiction between XPS and MS data can be explained due to diffusion limitations of ethylene oxide in the gas phase at $420 \mathrm{~K}$. After it is produced at the silver surface, it might accumulate in the volume above the sample surface where the gas phase is probed by XPS. Disappearance of this signal at $\mathrm{T}=470 \mathrm{~K}$ can be explained by the reduction of the viscosity of gas phase at higher temperature that would reduce the diffusion 
Table 1: Assignment of the C1s and O1s peaks to surface species observed during ethylene epoxidation over silver. Binding energies are given in $\mathrm{eV}$.

\begin{tabular}{|c|c|c|c|c|}
\hline Surface species & O1s BE & C1s BE & $\begin{array}{c}\text { Temperature range } \\
\text { of observation }\end{array}$ & References \\
\hline Carbon contaminants & - & 284.2 & $\mathrm{~T}<420 \mathrm{~K}$ & 6 \\
\hline Surface carbonates & 530.5 & 287.3 & $\mathrm{~T}<420 \mathrm{~K}$ & $6,31-34$ \\
\hline Nucleophilic oxygen & 528.3 & - & $\mathrm{T} \geq 420 \mathrm{~K}$ & $7,9,10,32,33$ \\
\hline Electrophilic oxygen & 530.0 & - & $\mathrm{T} \geq 420 \mathrm{~K}$ & $7,9,10,42,43$ \\
\hline O $\gamma$ & 529.1 & - & $\mathrm{T} \geq 470 \mathrm{~K}$ & 44,45 \\
\hline Embedded oxygen & 530.6 & - & $\mathrm{T} \geq 470 \mathrm{~K}$ & 44 \\
\hline
\end{tabular}

limitation. Since this explanation is not completely convincing, we made reference measurement when individual flows of pure ethylene oxide and other possible products were loaded to the gas cell of our spectrometer. It has been shown that only ethylene oxide exhibits similar binding energy values. Other possible products which could be a reason of this gas phase signal $\left(\mathrm{CO}, \mathrm{CO}_{2}\right)$ exhibit higher $\mathrm{BE}$ values. It has been also observed that acetaldehyde, which is often considered as a main intermediate in the route of ethylene oxide combustion [3-5], is characterized by two different features in the $\mathrm{C} 1 \mathrm{~s}$ spectrum originating from nonequivalent carbon atoms in $\mathrm{CH}_{3}-\mathrm{CH}_{2}=\mathrm{O}$. All these data are in full agreement with literature [37]. XPS observation of gas phase ethylene oxide is of great significance since it allows an unambiguous identification of the PTRMS signal at $\mathrm{m} / \mathrm{z}=45$ (fig.1) as ethylene oxide, but not as acetaldehyde. Technically, these isomers exhibit very similar mass spectra [38].

The assignments of other $\mathrm{C} 1 \mathrm{~s}$ and $\mathrm{O} 1 \mathrm{~s}$ features observed in our experiments are summarized in Table 1. Additional criterion, which reinforced the assignment, was the temperature range in which they occurred. For example, assignment of an $\mathrm{O} 1 \mathrm{~s}$ feature at $\sim 530.5 \mathrm{eV}$ and a $\mathrm{C} 1 \mathrm{~s}$ feature at $\sim 287.5 \mathrm{eV}$ observed at $\mathrm{T}=370 \mathrm{~K}$ to surface carbonates, $\mathrm{CO}_{3 \text {,ads }}[6,32-35]$, was based not only on the $\mathrm{BE}$ values, but also on their stability on silver surfaces at ambient temperatures only. At $420 \mathrm{~K}$, carbonates decompose to adsorbed oxygen and $\mathrm{CO}_{2}$, which desorbs from the surface [6,31-34]. As a consequence, the corresponding features disappear from the XPS spectra. Closeness of the O/C atomic ratio calculated from the corresponding XPS peak intensities $(2.8-2.9)$ to the stoichiometric one (3.0) confirms additionally this assignment. Due to its low binding energy, the additional $\mathrm{C} 1 \mathrm{~s}$ peak at $284.2 \mathrm{eV}$ observed in the same temperature range $(<420 \mathrm{~K})$ can be assigned to carbonaceous residues. The accumulation of carboncontaining contaminants of different nature (graphitic carbon, hydrocarbons, etc.) on silver surfaces at ambient temperatures is also a well known fact.
The absence of $\mathrm{C} 1 \mathrm{~s}$ features from surface species suggests that the $\mathrm{O} 1 \mathrm{~s}$ signals observed at $420 \mathrm{~K}$ and above are caused by oxygen species. According to our previous investigations [7,9,10], binding energies of 528.5 and 530.0 $\mathrm{eV}$ are indicative of two oxygen species, nucleophilic and electrophilic oxygen, respectively. The terms nucleophilic and electrophilic oxygen were introduced by Grant and Lambert [3] to designate the nature of the interaction of oxygen with ethylene. The nucleophilic oxygen is active in the nucleophilic attack of the $\mathrm{C}-\mathrm{H}$ bond, as the first step of $\mathrm{C}_{2} \mathrm{H}_{4}$ combustion $[3,39]$, whereas electrophilic oxygen participates in the electrophilic interaction with the $\mathrm{C}=\mathrm{C}$ double bond of ethylene [3]. A detailed comprehensive study of the nature of these atomic oxygen species by XPS, XAS, UPS and XANES can be found in our recent papers $[9,10]$. Briefly, nucleophilic oxygen has oxidic nature and is formed as result of silver surface reconstruction $[9,10,32$ $35]$ in the course of oxygen adsorption, while electrophilic oxygen is adsorbed on the silver surface without reconstruction. Electrophilic oxygen was identified as adsorbed oxygen by Rocca et al. using HREELS $[40,41]$ and Bukhtiyarov et al. using angle-dependent XPS [42] on the basis of room-temperature experiments on $\mathrm{O}_{2}$ adsorption at $\mathrm{Ag}(100)$ and $\operatorname{Ag}(111)$ single crystals surfaces. This oxygen species was also found by King et al. as a low-coverage phase $(\Theta<$ 0.25 ) in recent STM investigations [43,44].

The binding energy of the feature at $\sim 529.0 \mathrm{eV}$ is close to that of the so-called $\mathrm{O}_{\gamma}$ oxygen, which has been extensively studied by Schlögl et al. [45,46]. This species represents strongly bound atomic oxygen embedded in the outer layers of silver, with oxygen atoms occupying part of the silver positions in the silver crystal lattice. The peak at $530.5 \mathrm{eV}$ can be assigned to subsurface oxygen embedded in octahedral holes or $\mathrm{O}_{\beta}$ in our old classification [45]. The location of these oxygen species in the subsurface region is in line with its inactivity towards ethylene.

Fig. 3 shows $\mathrm{O} 1 \mathrm{~s}$ and $\mathrm{C} 1 \mathrm{~s}$ spectra from the polycrystalline silver foil measured in-situ at $420 \mathrm{~K}$, with $\mathrm{P}\left(\mathrm{O}_{2}\right)=$ 0.33 mbar and various ethylene partial pressures: $0 ; 0.03$; 0.1 ; and 0.24 mbar. The spectra measured in UHV before 


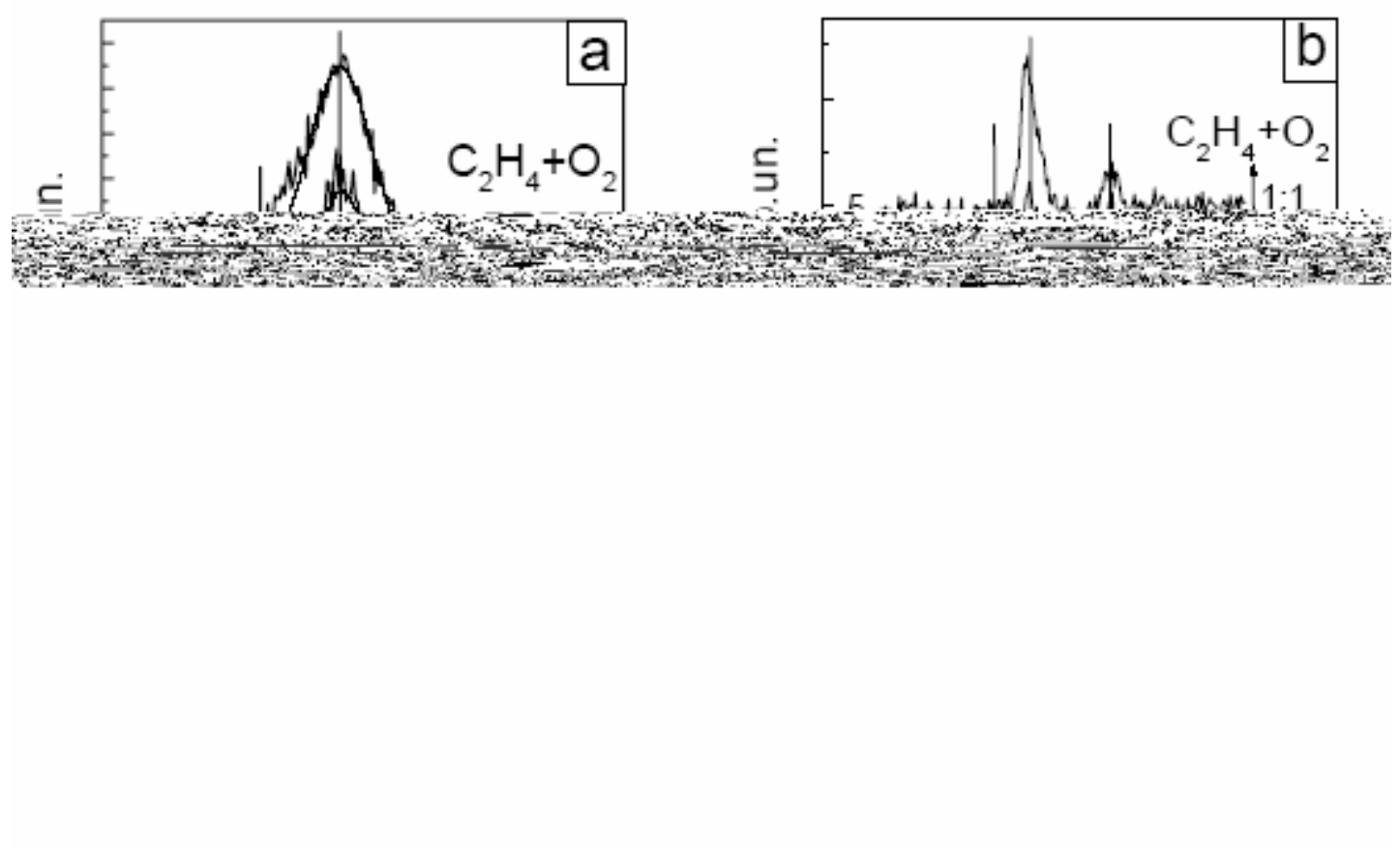

Figure 3: $\mathrm{O} 1 \mathrm{~s}$ (a) and $\mathrm{C} 1 \mathrm{~s}$ (b) spectra measured in-situ in the reaction mixture at $420 \mathrm{~K}, \mathrm{P}\left(\mathrm{O}_{2}\right)=0.33$ mbar and various $\mathrm{P}\left(\mathrm{C}_{2} \mathrm{H}_{4}\right): 2-0$ mbar (pure $\left.\mathrm{O}_{2}\right) ; 3-0.03$ mbar (1:10); $4-0.1 \mathrm{mbar}(1: 3) ; 5-0.24 \mathrm{mbar}(1: 1)$. The spectra from initial, "clean" silver surface measured in UHV (1) are also shown for comparison.

the experiments in the reaction mixtures are also shown for comparison. The initial silver surface measured in UHV was free from oxygen, but contained some carbonaceous residues (Fig. 3, curves 1). When oxygen is admitted to the chamber, the carbon contamination is removed and nucleophilic oxygen $(\mathrm{BE}=528.3 \mathrm{eV})$ is formed on the silver surface. (Fig. 3, curves 2). Introduction of ethylene to the gas flow transforms the spectra. Even the smallest partial pressure of ethylene $\left(\mathrm{P}\left(\mathrm{C}_{2} \mathrm{H}_{4}\right) / \mathrm{P}\left(\mathrm{O}_{2}\right)=1: 10\right)$ reduces the $\mathrm{O} 1 \mathrm{~s}$ signal from nucleophilic oxygen and leads to the appearance of a new peak at $530.0 \mathrm{eV}$ (Fig. 3a, curve 3) which is due to electrophilic oxygen, as discussed above. An increase in the partial pressure of ethylene up to $\mathrm{P}\left(\mathrm{C}_{2} \mathrm{H}_{4}\right) / \mathrm{P}\left(\mathrm{O}_{2}\right)=1: 3$ and further to $1: 1$ leads to a reduction of the surface concentration of the nucleophilic oxygen and an increase in the coverage by the electrophilic oxygen. Signals from gas phase ethylene $(285.8 \mathrm{eV})$ and ethylene oxide $(287.9 \mathrm{eV})$ are observed in the $\mathrm{C} 1 \mathrm{~s}$ spectra for all partial pressures of ethylene (Fig. $3 \mathrm{~b}$, curves 3 to 5 ). The intensity of the peak at $\mathrm{BE}=285.8 \mathrm{eV}$ is increased with raising $\mathrm{C}_{2} \mathrm{H}_{4}$ pressure, confirming the assignment of this peak to gas phase ethylene.

Ag3d $d_{5 / 2}$ spectra measured simultaneously with the $\mathrm{O} 1 \mathrm{~s}$ and $\mathrm{C} 1 \mathrm{~s}$ spectra in Fig. 3 are shown in Fig. 4. The spectrum measured in vacuum before the experiments in the reaction mixtures is also shown (Fig.4, curve 1). We have used this spectrum for comparison with the $\mathrm{Ag} 3 \mathrm{~d}_{5 / 2}$ spectra taken in-situ; for comparison the UHV $\mathrm{Ag} 3 \mathrm{~d}_{5 / 2}$ spectrum is shown with open circles together with the insitu spectra. The formation of nucleophilic oxygen upon introduction of oxygen at $420 \mathrm{~K}$ broadens the $\mathrm{Ag} 3 \mathrm{~d}_{5 / 2}$ spectrum as compared to the spectrum taken in UHV (Fig.4,

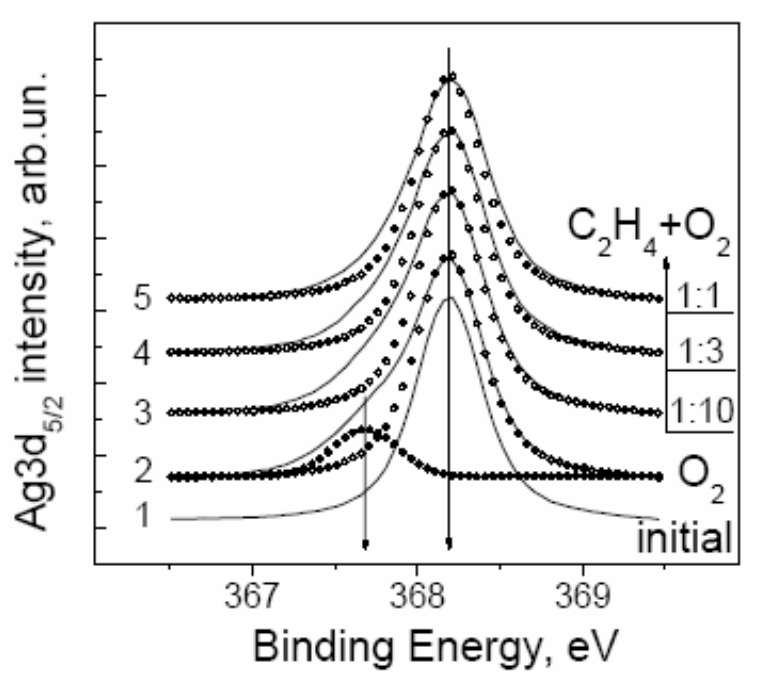

Figure 4: $\mathrm{Ag} 3 \mathrm{~d}_{5 / 2}$ spectra measured in-situ under the reaction

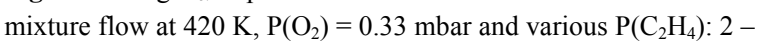
0 mbar $\left(\mathrm{O}_{2}\right) ; 3-0.03$ mbar $(1: 10) ; 3-0.1$ mbar $(1: 3) ; 4-0.24$ mbar (1:1). The spectrum measured from initial, "clean" silver surface measured in UHV is shown as curve 1. For direct comparison with the spectra measured under reaction conditions it is plotted several times as open circles. Difference spectrum (full circles) between measurements in pure $\mathrm{O}_{2}(2)$ and in UHV (1) shows the $\mathrm{Ag}_{3} \mathrm{~d}_{5 / 2}$ component associated with nucleophilic oxygen.

curve 2). The difference spectrum (full circles) shows that this broadening is due to the appearance of a new feature at $367.65 \mathrm{eV}$. This feature is a clear indicator of silver ions $\mathrm{Ag}^{\delta+}[7,10,43,44,47]$. Using XPS signals from the nucleophilic oxygen (Fig. 3a) and from ionic silver (Fig. 4, differ- 
ence spectrum), we calculated the $\mathrm{O} / \mathrm{Ag}$ atomic ratio, which was close to 0.5 . This value indicates that one species of nucleophilic oxygen produces two silver ions. This suggests the formation of an $\mathrm{Ag}_{2} \mathrm{O}$ surface oxide.

Adding 0.03 mbar ethylene to the oxygen flow reduces both the $\mathrm{O} 1 \mathrm{~s}$ intensity at $528.3 \mathrm{eV}$ (Fig. 3a, curve 3) and the $\mathrm{Ag} 3 \mathrm{~d}_{5 / 2}$ intensity at $367.6 \mathrm{eV}$ (Fig. 4, curve 3 ) so that the $\mathrm{O} / \mathrm{Ag}$ atomic ratio of the nucleophilic oxygen to ionic silver remains constant. This is also valid for the reaction mixtures with 0.1 and 0.24 mbar of ethylene (Figs. 3a and 4, curves 4 and 5). These results indicate that there is a correlation between the amount of $\mathrm{Ag}^{\delta+}$ ions and the concentration of nucleophilic oxygen.

\section{Discussion}

The results presented in the previous section showed that using in-situ XPS we have characterized the chemical composition of a catalytically active silver surface during ethylene epoxidation. It should be noted that similar PTRMS data have been obtained in the absence of X-rays indicating the absence of beam-induced effects on catalytic properties of the silver. A simple comparison of the catalytic (Fig. 1a) and spectroscopic (Fig. 2) data allows us to propose a preliminary explanation for the temperatureinduced variation of the catalytic properties of silver. The low activity of silver at $\mathrm{T}<420 \mathrm{~K}$ is caused mainly by the presence of carbonates and carbonaceous residues at the silver surface that reduce the available silver surface area for the catalytic reaction. When those contaminations are removed from the surface at $\mathrm{T}=420 \mathrm{~K}$, the silver surface becomes catalytically active for ethylene oxide formation (see Fig. 1a). The presence of nucleophilic and electrophilic oxygen at the active silver surface suggests that they participate in the ethylene oxidation reaction. The enhancement of the ethylene oxide yield at $\mathrm{T}>420 \mathrm{~K}$ is most likely determined by the Arrhenius dependence of the reaction rate on temperature. The decrease of the rate of ethylene oxide formation with time observed for $\mathrm{T} \geq 470 \mathrm{~K}$ can be explained by the accumulation of embedded oxygen species at the silver surface which decrease the surface area that is available for the formation of the active species. Nucleophilic and electrophilic oxygen, which were the main species at $420 \mathrm{~K}$, are still present on the silver surface at $470 \mathrm{~K}$; however, they are rapidly removed in the absence of oxygen in the gas phase (see the difference spectrum in Fig. 2a). These observations confirm the reactivity of nucleophilic and electrophilic oxygen species towards ethylene.

In order to elucidate the role of these species in the mechanisms of ethylene epoxidation, a quantitative comparison of the XPS and MS data is necessary. As quantitative measure of the surface concentration of oxygen species the intensity of the corresponding O1s peak normalized to

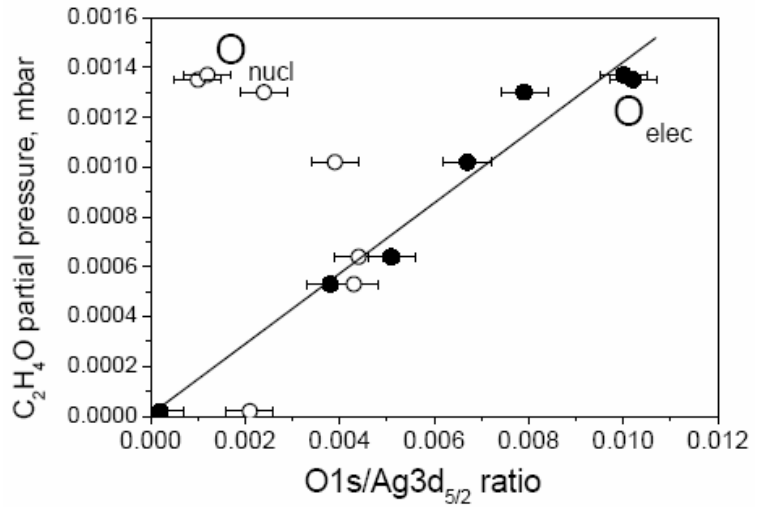

Figure 5: The yield of ethylene oxide as a function of the abundance of the nucleophilic (open symbols) and the electrophilic (full symbols) oxygen. All measurements were performed at $420 \mathrm{~K}$ and at various partial pressures of oxygen and ethylene (see the text).

the $\operatorname{Ag} 3 \mathrm{~d}_{5 / 2}$ intensity was used. The normalization was necessary to take into account the effect of attenuation of the photoelectrons in the gas phase which is quite sensitive to the pressure in the millibar range. Since the kinetic energies of $\mathrm{Ag} 3 \mathrm{~d}_{5 / 2}$ and $\mathrm{O} 1 \mathrm{~s}$ photoelectrons during measurement were the same (see Experimental), so their attenuation in gas phase should be also similar. Consequently, the $\mathrm{O} 1 \mathrm{~s} / \mathrm{Ag} 3 \mathrm{~d}_{5 / 2}$ atomic ratios should not depend on pressure of the gas phase. The yield of ethylene oxide was expressed as partial pressure of ethylene oxide recalibrated from PTRMS signals in accordance with the procedure described in Experimental. A comparison of the $\mathrm{C}_{2} \mathrm{H}_{4} \mathrm{O}$ yield with the abundance of nucleophilic and electrophilic oxygen for the experiments at $420 \mathrm{~K}$ is shown in Fig. 5. One can see a clear correlation between the abundance of the electrophilic oxygen and the yield of $\mathrm{C}_{2} \mathrm{H}_{4} \mathrm{O}$ : the higher the $\mathrm{O} 1 \mathrm{~s} / \mathrm{Ag} 3 \mathrm{~d}_{5 / 2}$ atomic ratio for this oxygen, the higher the partial pressure of ethylene oxide. This dependence is easily approximated by a straight line which aspires to point of origin. The revealed linear correlation can be interpreted as participation of the electrophilic oxygen in production of ethylene oxide. This conclusion is in full agreement with the results of our previous experiments on monitoring of the isotope composition of $\mathrm{CO}_{2}$ and $\mathrm{C}_{2} \mathrm{H}_{4} \mathrm{O}$ produced as temperature programmed reaction (TPR) of ethylene coadsorbed with the isotopically labeled oxygen species: electrophilic oxygen was prepared with ${ }^{16} \mathrm{O}_{2}$ and nucleophilic oxygen - with ${ }^{18} \mathrm{O}_{2}$ [48]. It has been shown that only electrophilic oxygen labeled as ${ }^{16} \mathrm{O}$ interacts with ethylene resulting in $\mathrm{C}_{2} \mathrm{H}_{4}{ }^{16} \mathrm{O}$, while no signal from $\mathrm{C}_{2} \mathrm{H}_{4}{ }^{18} \mathrm{O}$ was observed in TPR spectra.

A more complicated dependence of ethylene oxide yield versus of the oxygen abundance is observed for the nucleophilic oxygen (fig.5). Although different ethylene oxide yields $\left(0.0013\right.$ and $<10^{-5}$ mbar $)$ can correspond to similar abundances of nucleophilic oxygen $\left(\mathrm{I}(\mathrm{O} 1 \mathrm{~s}) / \mathrm{I}\left(\mathrm{Ag} 3 \mathrm{~d}_{5 / 2}\right) \sim 0.02\right.$, general trend is a reduction of 


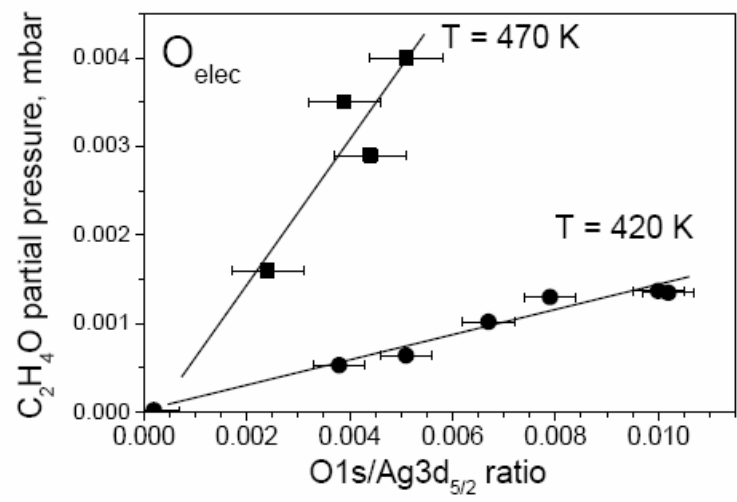

Figure 6: The yield of ethylene oxide as a function of the abundance of the electrophilic oxygen measured at different temperatures: $420 \mathrm{~K}$ (circles) and $470 \mathrm{~K}$ (squares).

the yield of ethylene oxide if the surface concentration of the nucleophilic oxygen is raised. This result can be explained by earlier reported activity of nucleophilic oxygen in total oxidation of ethylene only. Indeed, all attempts to produce ethylene oxide via titration of nucleophilic oxygen with ethylene have been unsuccessful [7,33-35]. $\mathrm{CO}_{2}$ and water were the only products of such a titration. Moreover, already mentioned isotope experiments [48] have shown that ${ }^{18} \mathrm{O}_{\text {nucl }}$ incorporates to $\mathrm{C}^{18} \mathrm{O}_{2}$, but not to $\mathrm{C}_{2} \mathrm{H}_{4}{ }^{18} \mathrm{O}$.

Although the presence of embedded oxygen species at $470 \mathrm{~K}$ reduced the accuracy of determination of concentrations of the surface species, we tried to plot the same dependence of ethylene oxide yield on abundance of electrophilic oxygen measured at $\mathrm{T}=470 \mathrm{~K}$. Fig. 6 compares this dependence with that measured at $420 \mathrm{~K}$. One can see that again there is the linear correlation between catalytic properties of silver in ethylene oxide production and the abundance of electrophilic oxygen:

$$
W_{\text {epox }}=A_{T} \times \Theta\left(O_{\text {elec }}\right),
$$

where $A_{T}$ is the coefficient of proportionality; index $\mathrm{T}$ reflects the variation of A with temperature. This result is an additional argument in favor of our hypothesis that namely this oxygen species epoxidizes ethylene. Other observation, which follows from Fig.6, is the fact that increase in temperature enhances the slope of the correlation observed. The ratio of the slopes determined at 470 and 420 $\mathrm{K}\left(\mathrm{A}_{470} / \mathrm{A}_{420}\right)$ is equal to 5.85 .

Since the measure of the rate of ethylene epoxidation $\left(\mathrm{W}_{\text {epox }}\right)$ is the EtO partial pressure in the reaction cell and $\mathrm{A}$ is proportional to the reaction constant, so the variation of the slopes of the observed correlations with temperature can be used for estimation of activation energy of the ethylene epoxidation:

$\mathrm{P}\left(\mathrm{C}_{2} \mathrm{H}_{4} \mathrm{O}\right)_{\mathrm{Ti}} \sim \mathrm{k}_{0} \times \exp \left(-\mathrm{E}_{\mathrm{a}} / \mathrm{RT}_{\mathrm{i}}\right) \times \Theta\left(\mathrm{O}_{\text {elec }}\right)_{\mathrm{Ti}}$

where $\mathrm{k}_{0}$ is the pre-exponential factor, $\mathrm{T}_{\mathrm{i}}$ is the temperature at which the dependence of ethylene oxide yield versus coverage of electrophilic oxygen is determined. Consequently, the slope of the dependence of $\mathrm{P}\left(\mathrm{C}_{2} \mathrm{H}_{4} \mathrm{O}\right)$ vs $\Theta\left(\mathrm{O}_{\text {elec }}\right)$ will be in direct proportion to $\exp \left(-\mathrm{E}_{\mathrm{a}} / \mathrm{RT}\right)$. Then, the ratio of the slopes can be expressed as:

$$
\frac{A_{470}}{A_{420}}=\exp \left(-E_{a} / R \times\left(\frac{1}{470}-\frac{1}{420}\right)\right)
$$

This equation can be transformed for the determination of activation energy:

$$
E_{a}=\ln \left(A_{470} / A_{420}\right) \times R /\left(\frac{1}{420}-\frac{1}{470}\right) .
$$

Using this equation and known ratio of $\mathrm{A}_{470} / \mathrm{A}_{420}$ we calculated the activation energy which appeared to be equal to $14 \mathrm{kcal} / \mathrm{mol}$.

Similar estimation of the activation energy can be made for higher temperature range: from 470 to $520 \mathrm{~K}$. Experimental basis for this estimation is the results of experiment for which the PTRMS signals are shown in Fig. 1b. O1s spectra measured sequentially at $520 \mathrm{~K}$ reveal that a decrease of the partial pressure of ethylene oxide from 0.0069 to 0.0054 (Fig. 1b) due to deactivation is accompanied by a decrease in the abundance of the electrophilic oxygen from $\mathrm{I}(\mathrm{O} 1 \mathrm{~s}) / \mathrm{I}\left(\mathrm{Ag} 3 \mathrm{~d}_{5 / 2}\right)=0.0027$ to 0.0018 . If we plot these points in the same manner as two previous dependences and use point of origin as third point, we obtain again a good correlation between the ethylene oxide yield and the abundance of electrophilic oxygen. Linear anamorphosis of the $520 \mathrm{~K}$ dependence results in a line with slope which is 3.18 times higher than the slope at $470 \mathrm{~K}$. The introduction of this value of $\mathrm{A}_{520} / \mathrm{A}_{470}$ to the following equation:

$$
E_{a}=\ln \left(A_{520} / A_{470}\right) \times R /\left(\frac{1}{470}-\frac{1}{520}\right)
$$

leads to the activation energy value of $11.3 \mathrm{kcal} / \mathrm{mol}$.

Both the values are in very good agreement with activation energy values reported in literature for surface science experiments of ethylene epoxidation over bulk silver samples. For example, the value of $10.8 \mathrm{kcal} / \mathrm{mol}$ was determined by Grant and Lambert as activation energy of epoxidation pathway for $\operatorname{Ag}(111)$ at $500 \mathrm{~K}$ [3], whereas Campbell reported $17.3 \mathrm{kcal} / \mathrm{mol}$ for the same single crystal at $440 \mathrm{~K}$ [2]. More detailed analysis of the activation energy of ethylene epoxidation has been made by Stegelmann et al [14] using the microkinetic model developed by authors on the basis of surface science experiments. The authors have concluded that activation energy varies as a function of reaction conditions: raising the temperature and reducing the total pressure decreases the activation energy. These effects are due to an increasing number of free sites on silver surface accessible for the reaction. They calculated the variation of activation energy with temperature for high (close to industrial) and low (typical for surface science papers) pressures. Comparison of the activation energy values determined in our experiments, 58 and $47 \mathrm{~kJ}$ 
per mole, indicates their good agreement with the values taken from the Stegelman's paper for low pressure curve [14]: $64 \mathrm{~kJ} / \mathrm{mol}$ for $450 \mathrm{~K}$ and $48 \mathrm{~kJ} / \mathrm{mol}$ for $500 \mathrm{~K}$, respectively. All these data evidence again that namely the electrophilic oxygen epoxidizes ethylene to ethylene oxide.

In general, many statements of the microkinetic model developed in Stegelman's papers $[14,15,49]$ are in good agreement with the data obtained in the present paper which can serve as experimental basis of the model. The main idea of the model is that epoxidation and combustion go through common intermediate (oxametallacycle) as suggested by Campbell et al [1,2] and Barteau [11,12]. Oxametallacycle, which is produced in reaction of ethylene and electrophilic oxygen, can branch to ethylene oxide and to acetaldehyde. In the presence of oxygen acetaldehyde combusts rapidly to $\mathrm{CO}_{2}$ and $\mathrm{H}_{2} \mathrm{O} . \mathrm{CO}_{2}$ is also produced through a parallel pathway, presumably due to interaction of ethylene with nucleophilic oxygen.

Our experiments prove that the silver surface, which is active in ethylene epoxidation, really contains two types of oxygen species: nucleophilic and electrophilic oxygen with different O1s binding energy values. Namely abundance of the electrophilic oxygen $\left(\mathrm{E}_{\mathrm{b}}(\mathrm{O} 1 \mathrm{~s})=530.0-530.2\right.$ $\mathrm{eV})$ correlates with the yield of ethylene oxide. This result indicates unambiguously that this oxygen species epoxidizes ethylene to ethylene oxide. Unfortunately, insensitivity of PTRMS to $\mathrm{CO}_{2}$ did not allow us to measure the yield of $\mathrm{CO}_{2}$ and compare it with the abundance of electrophilic oxygen. Consequently, we could not check the idea that the same reaction intermediate produced as result of interaction of ethylene with electrophilic oxygen can leads to $\mathrm{CO}_{2}$ formation.

It should however noted that our previous isotope experiments published in [48] showed that the formation of $\mathrm{C}^{16} \mathrm{O}_{2}$ occurs together with $\mathrm{C}_{2} \mathrm{H}_{4}{ }^{16} \mathrm{O}$ as result of TPR reaction of ethylene with silver surface precovered with isotopically labeled oxygen layer $-{ }^{18} \mathrm{O}_{\text {nucl }}$ and ${ }^{16} \mathrm{O}_{\text {elec}}$. At that time we could not explain this result. But it becomes easy understandable if the same reaction intermediates could provide both epoxidation and combustion of ethylene. Unfortunately, the conditions ( $\mathrm{T}>400 \mathrm{~K}$ and $\mathrm{P}<1 \mathrm{mbar}$ ) studied in the present work did not allow us to observe any reaction intermediates and we could not prove the existence of oxametallacycle under the reaction conditions.

At the same time, we could show that nucleophilic oxygen or surface oxide $(528.2-528.5 \mathrm{eV})$, which is also produced on the silver surface under the reaction conditions studied, is active in total oxidation probably via parallel route. This means that this oxygen species, which has been studied many, many times in the past, has no direct concern to the ethylene epoxidation. Its possible role, proposed also in our previous papers $[7,10-11,48]$, could be a creation of $\mathrm{Ag}^{\delta+}$ sites for the adsorption of ethylene [50] that then can react with electrophilic oxygen to ethylene oxide in the reaction:

$$
\mathrm{O}_{\text {elec }}+\mathrm{C}_{2} \mathrm{H}_{4, \mathrm{ads}} \rightarrow \mathrm{C}_{2} \mathrm{H}_{4} \mathrm{O} \text {. }
$$

The preferential adsorption of ethylene on $\mathrm{Ag}^{\delta+}$ ions has been recently suggested by Bocquet et al. [51], who studied sequential adsorption of oxygen and ethylene on $\mathrm{Ag}(111)$ using STM and DFT calculations. The correlation of the ionic silver and the nucleophilic oxygen was also observed in our XPS experiments (see Figs. 3a and 4). This consideration suggests that nucleophilic oxygen is not involved in epoxidation step, but simply counts the number of active sites. Stegelmann et al [14] have concluded that ethylene can adsorb both on surface oxide and on metallic silver. However, they also have shown that the contribution of the latter route of ethylene adsorption is much less important in mbar pressure range than the route in the presence of surface oxide [15].

The main discrepancy between the present work and the microkinetic model developed in $[14,15,49]$ is an interrelation between electrophilic and nucleophilic oxygen. Stegelman et al have proposed that electrophilic oxygen adsorbs on the surface oxide, in that way competing with ethylene for the surface sites. At the same time, our experiment at $420 \mathrm{~K}$ (fig.3) shows that increase of ethylene pressure in the $\mathrm{C}_{2} \mathrm{H}_{4}+\mathrm{O}_{2}$ reaction mixture replaces the nucleophilic oxygen with the electrophilic one. This result suggests that both nucleophilic and electrophilic oxygen are produced on metallic silver sites. This makes it difficult to explain which peculiarities of oxygen-silver bonding provide the formation of electrophilic oxygen. To clarify this problem the structure of its adsorption complex must be studied using such structural methods as scanning tunneling microscopy or photoelectron diffraction. It is evident that single crystal surfaces should be used as objects for such a study.

It should be however noted that that this study should be performed under the reaction conditions when mixture of ethylene with oxygen is interacted with silver. Indeed, high vacuum conditions will transform the oxygen overlayer. On the other hand, pure $\mathrm{O}_{2}$, which has been used and continues to be used in many investigations [ ] to form the oxygen overlayers, will result in formation of nucleophilic oxygen. However, as shown in the present study this oxygen species has no direct role in epoxidation of ethylene, and consequently any specification of its structure will have pure academic interest. Moreover, the study of electrophilic oxygen which is the species epoxidizing ethylene, will require in-situ measurements in millibar pressure range $(\mathrm{P}$ $>0.2-0.3$ mbar). In our low pressure experiment carried out at $\mathrm{P}_{\text {total }}=0.071 \mathrm{mbar}$, electrophilic oxygen was not observed in O1s spectra, although nucleophilic oxygen was produced with measurable abundance: $\mathrm{I}(\mathrm{O} 1 \mathrm{~s}) / \mathrm{I}\left(\mathrm{Ag} 3 \mathrm{~d}_{5 / 2}\right)=$ 0.0021 . In full agreement with low concentration of electrophilic oxygen (less than the XPS sensitivity limit), no PTRMS signal from ethylene oxide was not observed at this pressure (see points in Fig.5 with zero activity). 


\section{Summary}

We have performed first combined in situ XPS and PTRMS experiments of an active silver surface during the catalytic epoxidation of ethylene to ethylene oxide. Ethylene oxide was observed among the reaction products at $\mathrm{T} \geq$ $420 \mathrm{~K}$ and $\mathrm{P} \geq 0.3$ mbar. The comparison of the chemical composition of the silver surface taken from in-situ XPS measurements with the mass spectrometry data showed a correlation between the yield of ethylene oxide and the abundance of electrophilic oxygen characterized by $\mathrm{E}_{\mathrm{b}}(\mathrm{O} 1 \mathrm{~s})=530-530.2 \mathrm{eV}$. The correlation, which was observed both for 420 and for $470 \mathrm{~K}$ and was explained by participation of the electrophilic oxygen in ethylene epoxidation. The second surface oxygen species, nucleophilic oxygen $(528.2-528.4 \mathrm{eV})$, is active in ethylene combustion. Accumulation of other species at $\mathrm{T} \leq 370 \mathrm{~K}$ (carbonates, carbonaceous species) and at $\mathrm{T} \geq 470 \mathrm{~K}$ (embedded $\mathrm{O}_{\gamma}$ and $\mathrm{O}_{\beta}$ oxygen species) reduces the available silver surface

\section{References and Notes}

[1] C.T. Campbell, M.T. Paffett, Surf. Sci. 139 (1984) 396-416.

[2] C.T. Campbell, J. Catal. 94 (1985) 436-444.

[3] R.B. Grant, R.M. Lambert, J. Catal. 92 (1985) 364-375.

[4] R.A. van Santen, C.P.M. de Groot, J. Catal. 98 (1986) 530539.

[5] R.A. van Santen, H.P.C.E. Kuipers, Adv. Catal. 35 (1987) 265-321.

[6] A.I. Boronin, V.I. Bukhtiyarov, A.L. Vishnevskii, G.K. Boreskov, V.I. Savchenko, Surf. Sci. 201 (1988) 195-210.

[7] V.I. Bukhtiyarov, A.I. Boronin, I.P. Prosvirin, V.I. Savchenko, J. Catal. 150 (1994) 262-273.

[8] B.S. Bal'zhinimaev, Kinet. Catal. 40 (1999) 795-810.

[9] V.I. Bukhtiyarov, M. Hävecker, V.V. Kaichev, A. KnopGericke, R.W. Mayer, R. Schlögl, Catal. Lett. 74 (2001) 121-125.

[10] V.I. Bukhtiyarov, M. Hävecker, V.V. Kaichev, A. KnopGericke, R.W. Mayer, R. Schlögl, Phys. Rev. B 67 (2003) 235422.

[11] S. Linic, M.A. Barteau, J. Am. Chem. Soc. 124 (2003) 310317.

[12] S. Linic, M.A. Barteau, J. Am. Chem. Soc. 125 (2003) 40344035.

[13] F.J. Williams, D.P.C. Bird, A. Palermo, A.K. Santra, R.M. Lambert, J. Am. Chem. Soc. 126 (2004) 8509-8514.

[14] C. Stegelmann, N.C. Schiødt, C.T. Campbell, P. Stoltze, J. Catal. 221 (2004) 630-649.

[15] C. Stegelmann, P. Stoltze, J. Catal. 226 (2004) 129-137.

[16] A. Knop-Gericke, M. Hävecker, Th. Schedel-Niedrig, R. Schlögl, Topics Catal. 10 (2000) 187-198.

[17] A. Knop-Gericke, M. Hävecker, Th. Schedel-Niedrig, R. Schlögl, Topics Catal. 15 (2001) 27-34.

[18] G.A. Somorjai, G. Rupprechter, J. Phys. Chem. B. 103 (1999) 1623-1638.

[19] G. Rupprechter, T. Dellwig, H. Unterhalt, H.-J. Freund, Topics Catal. 15 (2001) 19-26.

[20] W.K. Kuhn, J. Szanyi, D.W. Goodman, Surf. Sci. 274 (1992) L611-L618. area for the catalytic reaction and deactivates the silver catalyst.

Our experiments also show that the chemical composition of the active silver surface under reaction conditions is different from the chemical composition that is measured when only one reagent is present in the gas phase, or when the surface is measured under vacuum conditions. Both active oxygen species disappear from the XPS spectra. This underlines the importance for using in-situ methods to investigate the properties of active catalyst surfaces.

\section{Acknowledgements}

The authors thank the BESSY staff for the help in carrying out the experiments. V.I.B. and A.I.N. gratefully acknowledge the Max-Planck-Gesellschaft for financial support during their visit to the Fritz-Haber-Institute and at the experiments at BESSY.
[21] E. Ozensoy, D.C. Meier, D.W. Goodman, J. Phys. Chem. B 106 (2002) 9367-9371.

[22] C. Sachs, M. Hillebrand, S. Völkening, J. Wintterlin, G. Ertl, Science 293 (2001) 1635-1638.

[23] K.B. Rider, K.S. Hwang, M. Salmeron, G.A. Somorjai, J. Am. Chem. Soc. 124 (2002) 5588-5593.

[24] R.W. Joyner, M.W. Roberts and K. Yates, Surf. Sci. 87 (1979) 501-509.

[25] V.I. Bukhtiyarov, I.P. Prosvirin, E.P. Tikhomirov, V.V. Kaichev, A.M. Sorokin and V.V. Evstigneev, React. Kinet. Catal. Lett. 79 (2003) 181-188.

[26] D.F. Ogletree, H. Bluhm, G. Lebedev, C.S. Fadley, Z. Hussain, M. Salmeron, Rev. Sci. Instrum. 73 (2002) 3872-3877.

[27] H. Bluhm, M. Hävecker, A. Knop-Gericke, E. Kleimenov, R. Schlögl, D. Teschner, V.I. Bukhtiyarov, D.F. Ogletree, M. Salmeron J. Phys. Chem. B. 108 (2004) 14340-14347.

[28] E. Kleimenov, H. Bluhm, M. Ндvecker, A. Knop-Gericke, A. Pestryakov, D. Teschner, J. A. Lopez-Sanchez, J. K. Bartley, G.J. Hutchings, R. Schlögl, Surf. Sci. 575 (2005) 181-188

[29] E. Kleimenov, PhD thesis, Technischen Universität Berlin, 2005, published online: http:// edocs.tuberlin.de/diss/2005/kleimenov_evgueni.pdf

[30] W. Lindinger, A. Hansel, A. Jordan, Chem. Soc. Rev. 27(1998) 347-354.

[31] K.J.S. Sawhney, F. Senf, W. Gudat, Nucl. Instrum. Meth. A 467 (2001) 466-469.

[32] M.A. Barteau and R.J. Madix, in The Chemical Physics of Solid Surfaces and Heterogeneous Catalysis, edited by D.A. King and D.P. Woodruff (Elsevier, Amsterdam, 1982), Vol. 4, chapter 4.

[33] C.T. Campbell, M.T. Paffett, Surf. Sci. 143 (1984) 517-535.

[34] C.T. Campbell, Surf. Sci. 157 (1985) 43-60.

[35] Backx, C.P.M. de Groot, P. Biloen, W.M.H. Sachtler, Surf. Sci. 128 (1983) 81-116.

[36] S. Linic, H. Piao, K. Adib, M.A. Barteau, Angew. Chem. Int. Ed. 43 (2004) 2918-2919. 
[37] K. Siegbahn, C. Nordling, G. Johansson, J. Hedman, P.F. Hedén, K. Hamrin, U. Gelius, T. Bergmark, L.O. Werme, R. Manne, and Y. Baer, "ESCA applied to free molecules", North-Holland, Amsterdam, 1969.

[38] http://www.nist.gov/srd/nistla.htm

[39] R.A. van Santen, S. Moolhuysen, W.M.H. Sachtler, J. Catal. 65 (1980) 478-480.

[40] M. Rocca, L. Savio, L. Vattuone, U. Burghaus, V. Palomba, N. Novelli, F. Buatier de Mongeot, U. Valbusa, Phys. Rev. B 61 (2000) 213-227.

[41] L. Savio, L. Vattuone, M. Rocca, F. Buatier de Mongeot, G. Comelli, A. Baraldi, S. Lizzit, G. Paolucci, Surf. Sci. 506 (2002) 213-222.

[42] V.I. Bukhtiyarov, V.V. Kaichev, I.P. Prosvirin, J. Chem. Phys. 111 (1999) 2169-2175.

[43] C.I. Carlisle, D.A. King, M.-L. Bocquet, J. Cerda, P. Sautet, Phys. Rev. Lett. 84 (2000) 3899-3902.
[44] A. Michaelides, M.-L. Bocquet, P. Sautet, A. Alavi, D.A. King, Chem. Phys. Lett. 367 (2003) 344-350.

[45] X. Bao, M. Muhler, Th. Schedel-Niedrig, R. Schlögl, Phys. Rev. B 54 (1996) 2249-2262.

[46] Th. Schedel-Niedrig, X. Bao, M. Muhler and R. Schlögl, Ber. Bunsenges. Phys. Chem. 101 (1997) 994-1006.

[47] L.H. Tjeng, M.B.J. Meinders, J. van Elp, G.A. Sawatzky, R.L. Johnson, Phys. Rev. B 41 (1990) 3190-3199.

[48] V.I. Bukhtiyarov, I.P. Prosvirin, R.I. Kvon, Surf. Sci. 320 (1994) L47-L50.

[49] Stegelmann, P. Stoltze, J. Catal. 232 (2005) 444-446.

[50] W.M.H. Sachtler, C.Backx, R.A. van Santen, Catal. Rev-Sci. Eng. 23 (1981) 127-149.

[51] M.-L. Bocquet, P. Sautet, J. Cerda, C.I. Carlisle, M.J. Webb, D.A. King, J. Am. Chem. Soc. 125 (2003) 3119-3125. 